ARTICLE HISTORY: Received: September 13, 2021 Accepted: November 5, 2021 Published: November 13, 2021

УДК 140.8

\author{
ПОСТМОДЕРН И НИГИЛИЗМ \\ (СТРАТЕГИИ КРИТИКИ НИГИЛИЗМА В ФИЛОСФИИ Ж.-Ф.ЛИОТАРА)
}

Сидоров А.М.

кандидат философских наук, доцент,

Санкт-Петербургский государственный университет,

2. Санкт-Петербург

\title{
POSTMODERN AND NIHILISM (STRATEGIES OF CRITICISM OF NIHILISM IN THE PHILOSPHY OF J.-F. LYOTARD)
}

\author{
Sidorov A.M. \\ PhD in Philosophy, Docent, \\ Saint Petersburg State University, \\ Saint Petersburg
}

\begin{abstract}
Аннотация: Статья посвящена анализу темы нигилизма в постмодернистской философии на примере одного из ее главных представителей Ж.-Ф.Лиотара. Начиная с Ф.Ницше термин «нигилизм» использовался различными теоретиками для описания интеллектуальной и духовной ситуации западной цивилизации эпохи модерна. Последние десятилетия XX в. отмечены переходом к новой культурной парадигме постмодерна. Но и в постмодернистских теориях тема нигилизма не исчезла, а вызвала к жизни новые стратегии осмысления и критики. Ж.-Ф.Лиотар, ключевой теоретик постмодерна, на всех этапах своего творчества пытался понять, как изменилась нигилистическая логика развития цивилизации в «состоянии постмодерна». В статье раскрывается предложенный Лиотаром философский и политический ответ на вызов нигилистического подавления жизни системами капитала, технонауки и репрессивной рациональности.

Abstract: The article is devoted to the analysis of the theme of nihilism in postmodern philosophy on the example of one of its main representatives J.-F. Lyotard. Since F. Nietzsche, the term "nihilism" has been used by various theorists to describe the intellectual and spiritual situation of Western civilization in the era of modernity. The last decades of the twentieth century marked by the transition to a new cultural paradigm of postmodernity. But even in postmodernist theories, the topic of nihilism did not disappear, but gave rise to new strategies of comprehension and criticism. J.-F. Lyotard, a key theorist of postmodernity, at all stages of his work tried to understand how the nihilistic logic of the development of civilization in the "postmodern condition" has changed. The article reveals the philosophical and political response proposed by Lyotard to the challenge of the nihilistic suppression of life by the systems of capital, technoscience and repressive rationality.
\end{abstract}

Ключевые слова: постмодерн, нигилизм, либидинальная экономика, метанарратив, Лиотар

Key words: postmodern, nihilism, libidinal economy, metanarrative, Lyotard

Утверждение о том, что западная цивилизация переживает кризис смыслов, давно уже стало общепризнанным. Влияние господствовавших ранее социальных институтов, таких как христианская церковь, и традиционных ценностей, ассоциировавшихся с этими институтами, которые внушали людям чувство онтологической безопасности, оказалось подорвано этими переменами. Ницше и последовавшие за ним мыслители попытались философски осмыслить эту ситуацию отчаяния по поводу возможности прожить осмысленную жизнь в западной цивилизации, несмотря на все успехи науки и технологии, используя понятие «нигилизм». Ницше предсказал развитие нигилизма в течение последующих двух столетий («То, что я расскажу, - история двух следующих столетий. Я пишу о том, что наступает, что уже не может наступить иначе: надвигается нигилизм» [6, с. 31]). М.Хайдеггер, вслед за Ницше, писал: «Нигилизм - это движение в историческом совершении, а не какой-нибудь взгляд, не какое-нибудь учение, какие кто-либо разделял и каких кто-либо придерживался. Нигилизм движет историческое совершение, как может движить его еще почти не распознанный фундаментальный процесс внутри судьбы народов Запада. По этому же самому нигилизм и не только историческое явление наряду с другими, не только духовное течение, какое встречалось бы в истории Запада наряду с другими, наряду с христианством, гуманизмом, просвещением. Нигилизм, если мыслить его по его сущности, - это, скорее, основополагающее движение в историческом совершении Запада» [8, с.19]. Если Ницше не ошибся в хронологии, то мы сегодня находимся как раз в середине этого процесса. Каков статус нигилизма сегодня? Есть ли что сказать о нем современной, а точнее «постсовременной» теории? Тема 
нигилизма была неразрывно связана с историей модерна, но если теперь мы вступили в эпоху поздней или постсовременности, которая имеет свою специфику, то также должна была измениться и проблематика нигилизма.

За ответами на эти вопросы логичнее всего обратиться к работам философа, с чьим именем прежде всего связана легитимация термина «постмодерн» в современной философии. Речь идет о Ж.-Ф.Лиотаре, авторе этапной книги «Состояние постмодерна». Еще до анализа проблематики постмодерна, в своей ранней работе «Либидинальная экономика» Лиотар связывает нигилизм с характерной для западной культуры тенденцией подчинять непредсказуемую событийность жизни «репрезентационным системам», которые сводят жизнь к стерильности рационально объяснимых структур. Следовательно, столкновение Лиотара с проблемой нигилизма состоит в выполнении трудной задачи - критике репрезентации, при ясном понимании того, что этот способ мышления нельзя просто обойти и заменить каким-то другим «жизнеутверждающей» альтернативой. Лиотар продолжает ницшевскую критику нигилизма, дополняя ее психоаналитическим словарем: он говорит о противоречивых, напряженных отношениях между структурами (диспозитивами) и силой (либидинальной энергией). С точки зрения подобной «экономики» нигилизм предстает как понижение интенсивности желаний и аффектов. Структуры эффективно подавляют энергию либидо, которую они канализируют, и нигилизм, тем самым, прогрессирует. Концептом, выражающим максимум нигилистического подавления со стороны репрезентационных структур в этой ранней работе Лиотара является «Великий Нуль», выступающий в качестве «навязанного желанию онтологического мотива, чтобы постоянно все откладывать, пред-ставлять и симулировать...» [3, с. 17].

Однако Лиотар быстро делает важный ход, отвергая критику, как установку присущую тому самому нигилизму, который должен быть ниспровергнут. Критика в своей негативной функции - это реактивная позиция, и поэтому она неспособна содействовать утверждению жизни, которого ищут Ницше и Лиотар. В этом случае, анализировать нигилизм следует, не обвиняя его напрямую в реактивной, отрицательной установке, тем самым как бы занимая вакантное место остающееся «после» нигилизма. Хайдеггер сказал по поводу преодоления нигилизма следующее: «Никто не перепрыгнет через собственную тень» [7, с.271]. Само наше существование настолько обусловлено историей нигилизма, что все попытки преодоления только усиливают его. Избежать этой опасности можно размывая границы желанием и репрезентацией или либидо и структурой. Структуры должны быть поняты как либидинальные диспозиции, а не подвергаться критике и осуждению напрямую.

Для того, чтобы объяснить отношения между аффирмативными либидинальными энергиями и нигилистическими структурами так, чтобы не проводить жесткой границы между ними и избежать тем самым «религиозной» позиции критики, Лиотар вводит понятие «диссимуляции», то есть, притворства. Либидинальные энергии оформляются фигурами и диспозитивами в более или менее устойчивые структуры. Понятие диссимуляции указывает на тот факт, что структуры сами по себе являются либидинальными образованиями, то есть определенными конфигурациями желания. Более того, структуры утаивают энергию, которую они содержат, притворяясь неизменными, но энергия никогда не бывает стабильной: структуры могут быть разрушены потоками новых энергий или высвобождением уже имеющейся энергии. Демонстрация того, что структуры не бывают «чистыми», но всегда являются насыщены энергией либидо, позволяет Лиотару избежать позиции критики. Каждая структура - это проявление желания и, следовательно, обладает определенной ценностью с точки зрения «либидинального экономиста». С другой стороны, не существует и «чистой» энергии, которая не имела бы формы или содержания. О либидинальной энергии мы можем узнать только по ее проявлениям в структурах и посредством структур. Таким образом, Лиотар избегает создания ряда бинарных терминов, где одни бы доминировали, а другие обесценивались. Тем не менее критерии оценки существуют, и с точки зрения жизнеутверждения предпочтительны те структуры, которые более открыты для возникновения событий, понимаемых как интенсивные желании и энергии.

Таким образом, ответ Лиотара на проблему нигилизма не является простым «преодолением» или постулированием четкой альтернативы нигилизму. Нигилизм не может быть преодолен, поскольку движение «преодоления», негации - нигилистическое, по сути. Тем не менее, диссимуляция дает возможность проявиться различию в тождестве, случаю и событию в предустановленности системы, аффекту в разуме.

В «Состоянии постмодерна» Лиотар резко меняет словарь и форму философствования. Фрейда и Маркса сменяют Кант и Витгенштейн, а на смену эмоционально взвинченному стилю «Либидинальной экономики» приходит холодный беспристрастный анализ. Центральной темой исследования становится язык. Тем не менее, существует преемственность между «либидинальной» и «постмодернистской» фазами творчества философствования Лиотара, именно в ключевой теме соотношения между событиями и границами репрезенатции. В «Состоянии постмодерна» Лиотар развивает теорию о том, что наиболее развитые современные общества характеризуются разрывом с тем, к чему стремился и чем вдохновлялся модерн. Постмодерн характеризуется как новая эпоха в истории, когда развитие новых технологий и глобальной экономики изменяет статус знания. Именно в отношении этих социальных изменений Лиотар выдвигает теорию постмодерна, которую можно сравнить с теорией нигилизма Ницше. Лиотар эксплицитно делает такое сравнение, и это позволяет разобраться как наступление постмодерна повлияло на историю нигилизма на 
Западе. Лиотар описывает постмодерн как состояние культуры, возникшее в постиндустриальных обществах (то есть, наиболее технологически развитых обществах, в которых знание становится главной производительной силой) после Второй Мировой войны. Постмодерн характеризуется утратой веры в «метарассказы» как источник легитимации для социальных институтов и практик. То есть, его известнейшее определение постмодерна таково: «...Мы считаем «постмодерном» недоверие в отношении метарассказов» [5, с.10]. Эти метарассказы, или большие повествования, являются философиями истории, которые организуют все события и социальные проект в соответствии с постулируемой целью, и наделяют, таким образом эти события и действия смыслом. Модерн, современность - это господство таких больших историй, которые черпали свои идеи прогресса знания и социальной эмансипации из духа Просвещения и обращались к различным философским концепциям для обоснования своих целей. Лиотар перечисляет в каких философиях истории дается обоснование новоевропейской идее освобождения: в «христианском рассказе о первородном грехе и спасении через любовь, просвещенческом рассказе об освобождении от невежества и рабства через познание и равенство, философскоспекулятивном рассказе о реализации всеобщей Идеи через диалектику конкретного, марксистском рассказе об освобождении от эксплуатации и отчуждения через социализацию труда, капиталистическом рассказе об освобождении от бедности через техно-промышленное развитие» [4, с.41]. Все эти метанарративы в конечном счете являются секуляризированной версией христианского эсхатологического нарратива. Суть этого нарратива в том, что субъект поражен нехваткой, небытием (грехом и смертью), и будет спасен в конце времен. Несмотря на свое внешне нерелигиозное или антирелигиозное содержание, они рассказывают ту же фабулу, поскольку сохраняют эсхатологический принцип. Таким образом, мы видим, что метанарративы являются модернистской формой религиозного нигилизма, где вера в трансцендентный «истинный мир» становится верой в будущие утопии.

В эпоху постмодерна эти метанарративы легитимации утрачивают свое правдоподобие, или «делегитимизируются». Лиотар называет по крайней мере три причины этого процесса делигитимации. Первой причиной являются определенные исторические события XX века, которые проблематизируют каждый из «больших рассказов» современности». Для Лиотара историческая травма Освенцима является главным событием, указывающим на несостоятельность любой универсальной истории, в особенности любой телеологической и прогрессивной истории, поскольку такое событие в своей чудовищной несправедливости просто не может быть инкорпорировано ни в какой из рассказов о грядущем благе.

Во-вторых, Лиотар утверждает, что метанарративы содержат в самих себе начала собственной делегитимации. Именно в этом пункте он сравнивает процесс делегитимации с историей нигилизма, рассказанной Ницше, в которой высшие ценности, по сути, обесценивают сами себя. Объясняя процесс делегитимации, Лиотар обращается к двум господствующим нарративам легитимации, берущим начало в Просвещении и вдохновляющим модерн - спекулятивному и эмансипационному. Используя стратегию, характерную для этого этапа его мысли, Лиотар, обращаясь к теории языковых игр Витгенштейна и аналитической философии, показывает, что эти метанарративы состоят из двух и более языковых игр, то есть, они внутренне противоречивы и, следовательно, не могут обосновать знание.

В-третьих, делегитимация происходит из-за того, что наука и политическая экономия становятся все более автономными и обретают легитимность просто своим осуществлением, перформативно, не нуждаясь больше в метанарративах для обоснования. Сначала, наука в современности опиралась на идеи прогресса и свободы. Но в ходе индустриальной революции сферы науки, технологии и экономики оказались взаимосвязанными через применение машинной технологии в производстве, и это привело к изменениям формах легитимации. Наука и технология слились в единую «технонауку», которая исследует природу не для получения знания, а для технологических инноваций. Технонаука и капитал тоже составили пару - деньги развивают технологии, применение последних увеличивает богатство.

Более того, Лиотар отмечает сдвиг в технологических инновациях во второй половине XX века в сторону языка, информации и коммуникации. Это дало основания теоретикам постиндустриального общества, таким как Д.Белл или А.Турен утверждать, что главной движущей силой экономики становится не промышленность, а информация. Это меняет природу общества, поскольку социальные отношения становятся опосредованными коммуникацией и независимыми от традиционных регуляций. Поэтому постмодерн следует понимать как состояние общества, характеризующегося фрагментацией и плюрализацией языковых игр и форм жизни, которые не могут быть объединены метанарративами или традиционными социальными институтами и ценностями. Сам социальный субъект как бы растворяется в диссеминации языковых игр.

Хотя Лиотар во многом следует логике ницшевской истории нигилизма, описывая наступление постмодерна, важно понимать, что в его описании предстает следующая, новая стадия нигилизм, по сравнению с тем, что Ницше диагностировал в своих работах. Эта новизна заключается в разрыве с метанарративами модерна, которые являются секуляризированными формами идеи Бога. Ницше доказывал, что многие из кажущихся новыми особенностей современности в действительности повторяют логику религиозного нигилизма, постулируя трансцендентальные категории единства, цели и истины, придающих смысл существованию. Смысл постмодерна заключается как раз в обесценивании этих категорий, так что можно 
считать теорию постомодерна Лиотара констатацией того факта, что мы существенно продвинулись вперед по направлению к «совершенному» нигилизму. Но, в отличие от Ницше и многих других авторов, Лиотар не считает, что это состояние социальной фрагментации и утраты значений требует «преодоления». Скорее, постмодерн устраняет некоторые предпосылки для несправедливостей, сотворенных модерном.

При этом, не считая фрагментацию общества как таковую нигилистическим феноменом, Лиотар отмечает сохраняющиеся нигилистические тенденции и в постмодерне. Прежде всего они связаны с тем же симбиозом технонауки и капитала, который внес свой вклад в переход к постмодерну, и заключаются в редуктивных эффектах критерия перформативности. Так, в концепции Лиотара обнаруживается внутреннее напряжение. С одной стороны, вместе с концом метанарративов нигилизм приближается к своему завершению. С другой технонаука и капитал, которые как раз и поспособствовали делегитимации метанарративов, все-таки развивают и углубляют нигилизм на свой лад, редуцируя разнообразие жизни в соответствии с требованием эффективности. Это напряжение было и в либидинальной философии Лиотара, которая, хоть это и неочевидно, нашла продолжение в теории постмодерна. Функциональным эквивалентом метанарративов в ранней концепции Лиотара был, конечно же, Великий Нуль. И метанаративы, и Великий Нуль являются аналогами форм религиозного нигилизма и выражают трансцендентальные категории, которые «оформляют» события, понимаются ли они как либидинальные аффективные интенсивности, воплощающиеся в структурах или как (в «Состоянии постмодерна») лингвистические феномены, имеющие место в языковых играх. В либидинальной философии Лиотар высказывают идею, похожую на тезис о делегитимации метанарративов, рассматривая капитализм как силу, которая уничтожает архаические и домодерные традиции, и это уничтожение он приветствует (так же, как когда -то Маркс в «Манифесте Коммунистической партии»). Он пишет: «Следует приветствовать растворение форм и индивидов в обществе потребления» [9, с. 51], поскольку это означает разрушение барьеров и границ, которые воздвигаются потенциальным потокам либидинальной энергии Великим Нулем, господствующим в традиционных социальных, политических и теоретических репрезентационных структурах. То есть, капитализм действует как сила, углубляющая нигилизм, как активный нигилизм, который разрушает религиозный нигилизм. Лиотар приветствует процессы активного нигилизма, поскольку они сокрушают традиционные формы и позволяют свободнее циркулировать либидинальной энергии, энергии желаний, тем самым, способствуя жизнеутверждению.

Но, с другой стороны, сам капитализм - это, конечно же, форма нигилизма. С одной стороны, капитализм поощряет новые интенсивности, поскольку может использовать их в качестве новой энергии для раскручивания капиталистической машины (как, например, в музыкальной индустрии, когда ищутся новые звучания, возникают новые субкульутры и т.п., для того, чтобы подстегнуть желания потребителей), но сама эта эксплуатация интенсивностей в качестве товаров в системе экономического обмена стирает их особенности и различия. Так, капитализм сам становится нигилистическим Нулем, занимающим место религиозного.

Следовательно, в обоих случаях - и в «либидинальной» философии, и в теории постмодерна, Лиотар рассказывает историю о нигилизме, которая приводит к противоречию между разрушением старых нигилистических форм и возникновением новых, вследствие тех же caмblх процессов. Освобождающие силы становятся силами порабощающими. Разрушение традиционных форм значения и ценности открывает большие возможности для жизнеутверждения и справедливости, для свободной игры сил и событий. Поэтому наступление постмодерна - это позитивный исторический этап. Но нео-нигилизм в форме капитала и технонауки с их редуктивными критериями товарного закона стоимости и эффективности угрожают захватить место, оставшееся от метанарративов и религиозных форм Великого Нуля. Для Лиотара отход от «преодоления» нигилизма в политическом смысле предполагает перенос усилий с «макрополитики» правительств и институтов на «микрополитику» частных практик и действий. Для постмодернистов (не только для Лиотара, но, например, и для Ж.Бодрийяра [1], разрабатывавшего понятие соблазна как вариант политики активного недеяния, и для Ж.Делеза, создавшего вариант ницшеанской логики различия [2], и для Дж.Ваттимо, говорившего вслед за Хайдеггером о «превозмогании» нигилизма [10]) отказ от надежды на преодоление нигилизма означает также отказ от надежды на разрешение современной проблему утраты смысла путем смены социальной или политической формации. Возможность адекватного, не-нигилистического ответа на ситуацию нигилизма заключается в усилении либидинальной интенсивности в системах и структурах. Лиотаровский ответ на травму нигилизма принимает форму политики, но ее следует понимать как заговор перманентной революции внутри системы, но не как попытку окончательной революции, которая опрокинула бы существующий порядок и утвердила новый. Такого рода активность, как это не парадоксально на первый взгляд, с необходимостью включает в себя измерение пассивности. Причиной этого является то обстоятельство, что всплески либидинальной энергии, или события - явления непредсказуемые и спонтанные. Любая попытка сознательно и целенаправленно контролировать такие события чревата не просто неудачей, но и созданием структур, подавляющих витальность. «Активная пассивность» Лиотара предполагает ответ на травму модерна который не оказался бы в тупике активного нигилизма, «преодолевающего» нигилистический «Нуль» нигилистическим же способом, но способствовал бы максимизации и аффирмации интенсивностей жизни внутри существующих структур. 


\section{Список литературы:}

1. Бодрийяр Ж. Соблазн. - М.: Ад Маргинем, 2000. - 320 с.

2. Делез Ж. Ницше и философия. М.: Ад Маргинем, 2003.

3. Лиотар Ж.-Ф. Либидинальная экономика. М.-СПб.: Издательство Института Гайдара, 2018.

4. Лиотар Ж.-Ф. Постмодерн в изложении для детей. Письма 1982-1985. М.: Издательство РГГУ, 2008.

5. Лиотар Ж.-Ф. Состояние постмодерна. СПб.: Алетейя, 1998.

6. Ницше Ф. Воля к власти. М.: Культурная революция, 2016.

7. Хайдеггер М. Введение в метафизику. СПб.: Высшая религиозно-философская школа, 1998.

8. Хайдеггер М. Ницше и пустота. М.: Алгоритм, 2018.

9. Lyotard J.-F. Notes on Return and Kapital // Semiotexte, 3.1 (1978). C. 44-53.

10. Vattimo G. Nietzsche and Heidegger // Stanford Italian Review, 6.1-2 (1986). P. 28.

\section{References:}

1. Baudrillard J. Seduction. - Moskva: Ad Marginem, 2000. - 320 p.

2. Deleuze G. Nietzsche and philosophy. - Moskva: Ad Marginem, 2003. - 392 p.

3. Lyotard J.-F. Libidinal economy. - Moskva - Sankt-Peterburg: Izdatel'stvo Instituta Gajdara, 2018. $-472 \mathrm{p}$.

4. Lyotard J.-F. Postmodern, explained to children. - Moskva: Izdatel'stvo RGGU, 2008. - 145 p.

5. Lyotard J.-F. Postmodern condition. - Sankt-Peterburg: Aletejya, 1998. - 160 p.

6. Nietzsche F. Will to power. - Moskva: Kul'turnaya revolyuciya, 2016. - 824 p.

7. Heidegger M. Introduction to metaphysics. - Sankt-Peterburg: Vysshaya religiozno-filosofskaya shkola, 1998. $302 \mathrm{p}$.

8. Heidegger M. Nietzsche and emptiness. Moskva: Algoritm, 2018. $-288 \mathrm{p}$.

9. Lyotard J.-F. Notes on Return and Kapital // Semiotexte, 3.1 (1978). - P. 44-53.

10. Vattimo G. Nietzsche and Heidegger // Stanford Italian Review, 6.1-2 (1986). - P. 19-29. 